Res Publica. Revista de Historia de las Ideas Políticas ISSN-e: 1989-6115

http://dx.doi.org/10.5209/rpub.66187

\title{
Lo repulsivo: la señorita Schopenhauer
}

\author{
José Luis Villacañas Berlanga*
}

Recibido: 12 de junio de 2019 / Aceptado: 4 de octubre de 2019

Resumen. El artículo propone un acercamiento a Lotte en Weimar de Thomas Mann como una construcción mitológica que simboliza el comportamiento de Alemania ante la emergencia del nazismo. Cuando Mann tuvo que ofrecer un diagnóstico del final de la república de Weimar, situó a un Goethe viejo y solitario como el sabio dominador incomprendido de la pequeña ciudad, que por aquel entonces comenzaba a ser sitiada por las fuerzas del nacionalismo. Mann se sirve de la figura de Carlota, la vieja amante que cuarenta años después volvía a la ciudad. Ella, la heroína del Sturm und Drang no carente de sentido práctico y espíritu burgués, encarnaba el pasado, la Alemania eterna. Goethe, distanciado de su juventud y de su amante de entonces, representaba el espíritu europeo. Pero el artículo concede una especial atención a la figura de la señorita Schopenhauer, a la que Mann retrata con singular crueldad, como una figura de lo repulsivo. A través de estas figuras la obra de Mann presenta un agudo retrato del nacionalismo alemán y acaricia una genealogía del nazismo.

Palabras clave: Thomas Mann; Lotte en Weimar; Goethe; República de Weimar.

\section{[en] Repulsiveness: Miss Schopenhauer}

\begin{abstract}
The article proposes an approach to Thomas Mann's Lotte in Weimar as a mythological construction that symbolises Germany's behaviour faced with the emergence of Nazism. When Mann had to offer a diagnosis of the end of the Weimar Republic, he placed an old and lonely Goethe as the misunderstood genius dominating the small city, which was starting to be besieged by the forces of nationalism at the time. Mann makes use of the figure of Charlotte, Goethe's former beloved who returned to the city forty years later. The heroine of Sturm und Drang, lacking neither practical sense or bourgeois spirit, Lotte was the incarnation of the past, the eternal Germany. Goethe, distanced from his youth and his former lover, represented the European spirit. Yet this article pays special attention to the figure of Ms Schopenhauer, whom Mann portrays with singular cruelty, as a figure representing the repulsive. Through these figures, Mann's work presents an acute portrait of German nationalism and touches upon a genealogy of Nazism.
\end{abstract}

Keywords: Thomas Mann; Lotte in Weimar; Goethe; Weimar Republic.

Cómo citar: Villacañas, J.L. (2019). Lo repulsivo: la señorita Schopenhauer, en Res Publica 22.3, 745-754.

En un escrito anterior, dedicado a la figura del hombre carismático ${ }^{1}$, me he aproximado a la época en que Thomas Mann escribió Lotte en Weimar. Por supuesto no

\footnotetext{
UCM

1 J. L. Villacañas, "Thomas Mann y el hombre carismático. Reflexiones desde Weber”, en J. A. Roche, La sociología como una de las bellas artes, Barcelona, Anthropos, 2012, pp. 129-151.
} 
repetiré lo dicho en aquella ocasión. Sólo recordaré que Thomas Mann estaba por esta época muy influido por Karl Kerenyi y que tendía a aproximarse a la construcción literaria desde una elaborada comprensión de la mitología existencial. Por supuesto, esta comprensión del mito, la literatura y la vida ha tenido un tardío continuador en la figura de Hans Blumenberg, que siempre ha mostrado su sentido de la cercanía por su paisano, el descendiente de la familia senatorial de Lübbeck. Esta orientación mítica nos lleva a preguntarnos por la estructura simbólica de la novela. Como defendía en ese escrito que he citado, Thomas Mann se vio como el heredero de Goethe. Cuando ya en el exilio, Mann tuvo que ofrecer un diagnóstico del final de la república de Weimar, no tenía un mito más potente que situar a un Goethe viejo y solitario como el sabio dominador incomprendido de la pequeña ciudad, que por aquel entonces comenzaba a ser sitiada por las fuerzas del nacionalismo. Sin duda, debemos ver a Goethe, el profrancés, el amigo de Napoleón, el cosmopolita, el buen europeo, el antecesor de Nietzsche, como el espíritu de la República, que se había alojado en el alma del artista Thomas Mann mediante una de esas raras metamorfosis cercanas a la resurrección o a la reencarnación. La continuidad de estos personajes y de su función simbólica resultaba evidente y constituía el último paso de la identificación con la República, desde el lejano día en que Thomas Mann se había despedido de su impoliticidad conservadora y había celebrado a Novalis como el primer republicano alemán.

La situación que había que simbolizar era el exilio, desde luego, y sobre todo el fracaso de la República. En realidad, eran la misma cosa. El giro de significatividad que buscó Thomas Mann venía obligado porque Goethe nunca había estado en el exilio. Es más, por mucho que estuviera ausente, Goethe era el espíritu y este no se puede exiliar del mundo. Es el espíritu del mundo, como quedaría claro en los relatos posteriores, desde José y sus hermanos a El Elegido. Sobre todo en este último cuento medieval, el hegelianismo de la narración quedó patente de forma nítida. El espíritu no puede abandonar el mundo. De este modo, el personaje de Goethe tuvo que simbolizar el fracaso mediante la soledad y la incomprensión, aspectos que no impedían la admiración un tanto resentida de sus contemporáneos. Y algo del anhelo de un alma encerrada y solitaria hay en ese largo capítulo VII en el que Goethe se derrama por la pluma de Thomas Mann, mostrando los últimos secretos de su mente y entre ellos el fastidio por la llegada de su vieja amante Carlota, la heroína de Las penalidades del joven Werther. Un fastidio que estalla en una frase brutal por su sinceridad, cuando al final del capítulo exclama: "El pasado y la demencia se unen contra mí para engendrar la turbación y el desorden. ¿No pudo contenerse la vieja y haberme ahorrado esto?"2. La vieja, die Alte, es la antigua amante, cuarenta años después, que viene a la ciudad. En ella Mann expresa su fastidio ante el símbolo que representa el alma filistea de Alemania. Por eso la novela no se podía llamar "Goethe en Weimar". Desde un punto de vista estricto, Goethe siempre habitaría en Weimar, que de este modo se convertía en un lugar no alemán, un espacio universal, algo así como el Nazareth en el que el espíritu tomó cuerpo un día. Se trataba de novelar el hecho que producía desorden y turbación en las masas (siempre arremolinadas alrededor de Carlota, la heroína de la cultura Sturm), el símbolo de la emergencia y

Th. Mann, Lotte in Weimar, In der Fassung der Grossen kommentierten Frankfurter Ausgabe, Fischer Taschenbuch, Fankfurt, 2003, 367. Cf. Carlota en Weimar, traducción de R. Coll Robert, Ediciones Orbis, Barcelona, 1976, 234. En adelante, LW, y CW y números. 
poder de los nazis, la última consecuencia del estallido de lo demoniaco que arrasaba a las masas de filisteos alrededor de su heroína. Expulsado a la soledad, rodeado de fuerzas que no lo entienden ni lo comprenden, Goethe aparece condicionado por las masas que siguen a Carlota, como el propio Mann se veía obligado a abandonar Alemania presionado por las fuerzas imponentes de los nazis.

En esta situación, el encuadre mítico obligaba a simbolizar Alemania mediante la figura sobrecargada de Lotte. Así que la novela Lotte en Weimar venía a explicar el comportamiento de Alemania durante la República. Ella era el pasado eterno, la sustancialidad tradicional de Alemania, con ese aspecto no exento de cierta huella de belleza y dignidad, cierto, pero ya encorsetadas, inactuales, fetiches en suma sin vida íntima. Su comportamiento en los días de la visita de Goethe representaba lo que había sucedido con la república. Ella fue la heroína que probó los abismos del Sturm und Drang, pero que retrocedió hacia la vida convencional familiar de la eterna Alemania. Había conectado por un instante con la vida del genio, impulsado su despertar. Pero el genio ya estaba en otro sitio, conducido por su fidelidad a sí mismo como hombre universal. Aquella historia fue para él una de las inevitables payasadas de los jóvenes. Sin embargo, para otros, se convirtió en el modelo de prestigio y de cultura nacional, para todos esos que ahora querían conocer a la heroína, por mucho que ahora fuera un fantasma envejecido. Sin duda, Mann, como luego en Doktor Faustus, acaricia aquí una genealogía del nazismo como fantasma envejecido de lo demoníaco original, una impostura, un eco epigonal de los románticos con su profunda incomprensión del genio. Quizá con esto resulta conectado el momento de la novela en el que Goethe se lamenta del proyecto, fracasado desde luego, de acabar la obra de Schiller, Demetrio, que exponía la aguda percepción del carácter ficticio de todos los impostores aspirantes a la soberanía. No es casual que Carl Schmitt analizara a Demetrio como el arquetipo de la figura de Hitler.

Lotte es el pasado, la Alemania esencial, que mantiene en el fondo de su alma un eco las pulsiones irracionales del Sturm, pero que con buen sentido práctico, espíritu burgués, mentalidad tradicional, y "despierto sentido de ama de casa"3 logró sepultarlas en los días de la juventud. Todas las limitaciones del personaje tienen que ver con esto y ante todo el símbolo más preciso del encuentro con Goethe, el antiguo vestido del baile de Volpersthausen, aunque ya con las dudas de si debería llevar su viejo lazo rosa ${ }^{4}$ [LW, 239], algo así como el collar de la Kim Novack en Vértigo, pero sin la esmeralda, sin poder evocador, como un fetiche idólatra. Por eso Mann, a diferencia de Scottie Fergurson, en lugar de considerar ese lazo rosa como el objeto $a$, deja que la conciencia de Lotte, la hija, hable de él en términos de "los malditos lazos rosas" ${ }^{\prime 5}$ que el sabio Goethe hace como que no ve, sin dejarse atrapar por la melancolía estéril del que vive de las rentas del pasado. Él está en otra cosa. La larga comida del capítulo VIII es la prueba de esta incapacidad comunicativa. Lotte no entiende nada de lo que está pasando. Le gustaría coquetear de nuevo un poco con Goethe, realizar por fin su anhelo, que Goethe la sublime [LW, 83], que legitime su estatuto de símbolo nacional, que sea uno más de esa masa fanática. Ante esta oportunidad, Lotte siente en su seno "una obstinada alegría, furtiva y llena de esperanza" ${ }^{\text {; }}$ pero el

\footnotetext{
"Wahrend ihr Hausfrauensinn", dice maliciosamente Thomas Mann, LW, 396/ CW, 252.

Inicialmente, la voluntad de Carlota, según le cuenta a su hermana, es no llevar el lazo rosa. LW, 374/CW, 239.

“den vermaledeiten rosa Schleifen”, LW, 382/CW 244.

"ein Herzklopfen trotzig-diebischer und erwartungsvoller Freude verusrsachte", LW,377/CW241.
} 
genio -que conoce bien su alma vacía- sólo se preocupa de cumplir el expediente con buena educación, dirigiendo la ceremonia en todo momento, controlando el tiempo, imponiendo la conversación. Por supuesto, era el espíritu, en masculino, frente a Carlota, que era Alemania, la parte femenina. Respecto a esta contraposición, he aquí la conclusión: "Por lo demás, el elemento masculino del grupo legendario se había mostrado más apto para vivir, más capaz de durar, que la parte femenina"7.

Como ya había ocurrido en La Montaña Mágica, la construcción mitológica siempre acaba expresada en una teoría de arquetipos sexuales, que en Thomas Mann es compleja y plural porque al hombre y a la mujer, con todas sus ambivalencias, es preciso añadir el Fanciullo, el muchacho andrógino, con sus extrañas relaciones con las formas maduras de la existencia de uno u otro género, como se ve en Madame Chauchat. Todo lo que explica al personaje de Lotte tiene que ver con esta necesidad ceremoniosa de fingir para ocultar una completa inseguridad, una "tensión interior" que va creciendo, consecuencia de una falta de espíritu. Goethe, sin embargo, es el espíritu anhelante de mundo ${ }^{9}$. Así que la simbología del desencuentro de Goethe/Mann con Lotte/Alemania fanatizada en Weimar fue visto como un desencuentro entre sexos. En suma, como unas anti-afinidades electivas. Cuando Lotte ve de nuevo a Goethe tras cuarenta años, lo primero que proyecta tras su mirada es la expresión de extrañeza. "¿Quiénes son estas gentes?"10. Y en efecto, ¿qué afinidad electiva puede provocar un hombre que posee una "frente de piedra"? ${ }^{11}$, un guiño de Mann al Monsieur Teste de Valery, el también pendiente de hacerse con su propio Fausto.

En realidad, Carlota nunca tiene la impresión de que la esté mirando y, tan pronto puede, Goethe alza la vista para escapar de la sala, hacia las ventanas. Al final, tras la frase enigmática nietzscheana de que "los alemanes ofrecen una gran analogía con los chinos" 12 , la imaginación de Lotte desvaría y Mann no las presenta ausente y perdida, incapaz de continuar la conversación con el gran hombre, que conforme se anima la sesión, tras incontables copas, nos muestra su profunda dimensión dionisiaca, aproximándose a viejas escenas con espíritu ligero y cómico ${ }^{13}$. Al final, con una extrema crueldad, Mann conduce la velada a una escena despiadada en la que Goethe resuelve la realidad de la memoria a un montón de dispersas sombras chinescas, de siluetas recortadas. Abre el álbum en pleno desorden justo para que no se encuentren las propias siluetas de juventud, pero Carlota, que desea tener un lugar central en la memoria del gran hombre, las encuentra. Goethe queda contrariado. "Le estaba reservado a usted el encontrarlas", dice visiblemente molesto $^{14}$. Luego, sin solución de continuidad, para cerrar la fiesta le ofrece a Werner

"Übrhaupt hatte der männliche Teil jener bildhaft gewordenen Gruppe sich entscieden lebensbräver, zum Ausharren tüchtiger erwiesen, als der weibliche". LW, 372/ CW237.

8 "So kam, nur mit Zurückhaltung vor-erwähnt, eher in innerlich gespannten Schweigen erwartet, der Mittag oder Nchmittag dr ehrenvollen Einladung heran”. LW, 375/CW, 239.

9 "Este significativo rostro era "espíritu, maestría, historia, y esta marchitez, en vez de mover a compasión hacía palpitar con alegre espanto el corazón meditabundo" [LW, 247].

10 "Wer sind denn all die Leute". LW, 386/CW, 246.

11 "Eine solche Felsenstirn hatte er sonst keinesweg gehabt", LW, 387/CW, 247.

12 "Die Deutschen sind ein Volk, welches eine grosse Aehnlichkeit mir der Chinesen aufweist". LW, 411/CW, 262.

13 Sucede a a partir de la toma de los entremeses. Cf. LW, 417/CW, 265. "Trank rasch hinter einander, wie in Durst, zwei Spitzkelche davon: das geleete Glas hielt er dem Diener sogleich über die Schulten wieder hin".

14 Goethe queda asombrado de la capacidad de orientarse en el caos de imágenes a la búsqueda de la propia. "Ia ungläubig betrachtete, erwiderte er mit Resten von Aerger in der Stimme: 'Wahrhaftig, ja, Ihnen war's vorbe- 
visionar unas "babosas de agua dulce petrificadas". La frase está demasiado cerca como para no ver que eso es lo que realmente piensa Goethe del grupo de Lote. Por fin, una despedida formal hasta el extremo. La miseria vulgar del encuentro se desvela al final, cuando apreciamos el verdadero motivo del viaje. Lotte tenía la misión de recomendar a su pariente Ridel para un ascenso. Aunque al final no logra, intimar con Goethe siempre será ventajoso para otros fines, dice el afectado, con un sentido oportunista propio de su filisteísmo.

Como vemos, Thomas Mann nos ha mostrado su maestría a la hora de producir violencia a través del trato exquisito, algo completamente lejano de la barbarie nazi. Pero en esta lucha de sexos hay también una lucha de generaciones. Uno de los personajes mejor elaborados de la novela es casi una ausencia. Por supuesto no está entre las siluetas recortadas de la memoria de Goethe. Se trata de Lota, hija de Lotte. Goethe no sabe qué hacer con ella. Ya no tiene posibilidad de conducir una comunicación solvente. Por supuesto, ella contempla distante a su madre desde el principio al final, y ya en el carruaje se hace cargo de lo patético de la situación. Mann la ha dejado muda. A lo sumo ha permitido que se muerda los labios. Sin embargo, ha puesto en sus ojos toda la capacidad de desprecio posible. La diplomacia de Goethe se estrella en su silencio. Como consuelo ante su irritante juventud, Goethe solo tiene un recurso: "el tiempo lo aporta todo" ${ }^{15}$ ¿Pero se trata solo de la indisposición de la "rebelde pequeña Lota"? ¿O hay algo más?

Si Goethe es el espíritu que rueda por el tiempo ${ }^{16}$, la juventud alemana en Lote en Weimar es inquietante. Aunque por lo general dibuja personajes que están como ausente, tal y como sucede con la pequeña Otilia, la prometida imposible de Augusto, el único hijo reconocido de los que tuvo Goethe con la Vulpius, irrumpe en la novela de forma intensa, central, con la señorita Adela Schopenhauer, la clave de esta novela que bien podría llamarse Las afinidades electivas negativas. Su función es decisiva en toda la trama y, aunque no se nos cuenta el desenlace de sus esfuerzos, lo conocemos. Pues toda la aspiración de la señorita Schopenhauer es impedir por todos los medios que Augusto, el hijo de Goethe, se case con Otilia, y de este modo el espíritu reencarnado de Goethe pueda fructificar en Alemania. El desencuentro de Lotte con Goethe tiene que perpetuarse en el desencuentro de Augusto con Otilia. No deben existir dudas de la excepcionalidad del espíritu de Goethe. Se le reconoce porque, como dice Carlota, los alemanes "no son chinos que saltan y vociferan bajo sus tejados con campanillas, como viles mamarrachos" ${ }^{17}$. Ellos, los alemanes, saben reconocer al superior, dice Carlota situándose en un extraño lugar ${ }^{18}$. Pero a pesar de todo, no permitirán que se perpetúe su espíritu dominador sobre ellos. Pues ese espíritu, encarnado en Augusto, es el propio de un hijo natural con la infame y vulgar

halten, es ausfindig zu machen". LW, 425/CW, 270.

15 "Das herbe Lottchen" le llama en esta pasaje, en el que Goethe se muestra inseguro, para concluir con un "Harrt man nur aus, so bringt die Zeit alles heran". LW, 390/CW, 249.

16 El detalle de comparar las conversaciones de Goethe con las Tischenrede de Lutero contribuye a conformar esta impresión. Cf. LW403/CW257.

17 "Die Chinesen, wie sie da hüpfen und zirpen unter ihren Glockendächern,sind alberne, böse Menshcen”. Cf LW, 427/CW, 272.

18 Toda más marcado desde el momento en que ella tiene una relación especial con la bondad "Er ist gross, und ihr seid gut Aber ich bin auch gut, so recht von Herzen gut und will es sein". Cf LW, 427/CW, 272. El subrayado es mío 
Vulpius, "una simple hija del pueblo"19, alguien tan estigmatizado en su origen para los filisteos alemanes como la propia república popular de Weimar.

Esta es la tarea desestabilizadora de la señorita Schopenhauer, que ocupa toda la escena cuarta de este cuadro de costumbres, casi una crónica periodística de la buena sociedad. Carlota se resiste a recibirla. Está cansada y no sabe cómo reconducir la situación tras la larga conversación con el doctor Riemer. Ante su nombre, tan poderoso, el doctor le recomienda a Carlota que ceda y le conceda un tiempo de conversación. Se trata, dice, de "una señorita muy culta y que está muy bien relacionada, la hija de la señora Juana Schopenhauer, una vida rica de Danzig [...] mujer culta y espiritual" ${ }^{20}$. Al final la entrevista se produce sobre todo por la excitación y el ansia de protagonismo de Lotte. La descripción que Thomas Mann hace del encuentro es la siguiente: "Adela Schopenhauer hizo un profundo saludo. Carlota la saludó amablemente, tendiendo la mano. Vio que la visitante apenas si había pasado de los veinte años. No era nada bonita, mas parecía inteligente. Se esforzaba en disimular el ligero estrabismo de sus ojos, de un verde amarillo, tan pronto con un parpadeo precipitado como por rápidas miradas a su alrededor o al techo. Su expresión denotaba la vivacidad de su inteligencia; su boca, de fina sonrisa, grande y delgada, ejercitada en el arte de las conversaciones sutiles, no conseguía el olvido para su nariz alargada, el cuello, igualmente muy largo y las orejas, lamentablemente separadas bajo un sombrero de paja bastante original con guirnaldas de rosas. La jovencita tenía una silueta mezquina" ${ }^{21}$. La crueldad de Mann no tiene límites, pues sigue presentándonos detalles de su fisonomía claramente desagradables: espalda seca, brazos frágiles, hablar prolijo, incansable. "Su salivación era muy abundante", dice, y le daba a la conversación el aspecto de una fuente. Esta presencia repulsiva obligó a Carlota a experimentar "una secreta inquietud". Entre lo ridículo y lo imponente, o quizá por ser ambas cosas, producía un efecto de repulsión e hilaridad a la vez. Ese podría ser el efecto de su aspecto de pequeño diablillo insignificante y femenino. Su señora madre, conocida por sus artes sutiles, era su maestra. Era ella la que había conquistado a Goethe para su salón. A sus sesiones de té asisten además de los hermanos Schlegel, los Grimm y desde luego el fundador del derecho histórico, Savigny. De esta sociedad también habría podido decir Lukács que había algo de infame en el grupo. Podemos suponer lo que no puede entender ni aceptar la señorita Adela. Todo su contenido furor lo lanza contra la Vulpius, "glotona, abotargada, con las mejillas coloradas y obsesio-

19 La escena entre Augusto y Carlota es de una importancia extrema en la novela, pues muestra de forma clara las preferencia popular de Goethe y la herencia en cierto modo ilegítima, pero plenamente asumida, de su matrimonio con la Vulpius. El hijo, que en esta situación se muestra propenso a la ira, pero que ante todo reclama su adhesión a una Alemania que no es la propiamente burguesa de Carlota, se autoafirma y reconoce la grandeza de su padre, que en cierto modo lo constituye en su posición. Goethe habría vivido "gegen den Sittenkodex und hatte das einfache Mädchen aus del Volke zu sich genommen und vor ihren Augen mit ihr gelebt!" Cf LW, 237/ CW, 152.

20 Esta última expresión, que no es literal, se refiere a la madre Johanna, muy amiga de Goethe. Cf. LW, 128/CW, 86.

21 Cf. LW, 131-132/CW, 88. La imagen es cruel y casi demoníaca. Esos “gelb-grünen Augen”, esa "nervösen Intelligenz", o "die hängende Länge der Nase" o las "betrüblich abstehenden Ohren", o ese "etwas genialisch geformten Strohhut" culminan en el juicio sumarísimo "Die Gestalt des Mädchens war dürftig”. Thomas Mann sigue describiéndola con un claro sadismo. Habla de su "weisser aber flacher Busen" y de sus"mageren Schultern", de "die dünnen Arme", "rötliche Finger” y "weissen Nägeln”. Para más crueldad, le hace salivar abundantemente. No es de extrañar que ante ella, Carlota experimente una "heimliche Besorgnis". 
nada por la danza"22. En otros términos, no soporta su profunda afinidad dionisíaca y popular, que Thomas Mann se encarga de subrayar una y otra vez, vinculándola a la danza, la bebida, las francachelas estudiantiles y a los cómicos ambulantes. En un momento llega a llamarla "imagen misma de la vida" ${ }^{23}$. Lo repulsivo encuentra repulsiva la vida, anti-estética. Situada en el extremo completo de lo que la Vulpius representa, Adela no puede sino expresar su profundo desprecio. En este caso, implica su incapacidad de comprender a Goethe quien, una vez muerta, se lanzase sobre ella gritando "¡Tú no puedes! ¡Tú no puedes abandonarme!”"24.

La misión de Adela en este complejo sistema de símbolos es apagar la luz de la linterna de Goethe, con la que el genio verdadero iluminaba el camino en la noche. De Goethe por supuesto desprecia su amor a la risa y no entiende su predilección por aquella mujer carente de cultura. Estas inclinaciones de Goethe y su forma de administrarlas para seguir manteniendo la inspiración y el arte, le resultan a Adela un secreto insoportable, una falta de confianza instintiva del gran hombre en la gente como ella. "Hay una prevención doctoral casi grosera, un espíritu partidista del hombre que quisiera prohibirnos el acceso a las esferas superiores de la poesía y la inteligencia"25, dice con cierto aire autosuficiente, absoluto y remilgado, pero sobre todo radical, pues no puede dejar de apreciar esta actitud de Goethe como un "tiranía". Con esto comenzamos a identificar el otro aspecto del fastidio que siente Goethe en la situación. Lotta es el pasado. Adela Schopenhauer es la demencia. "Cabras sentimentales" llama Goethe/Mann a este tipo de mujer. Adela se defiende y asume que se trata de una lucha generacional. "Somos la generación que sube, no cabras sentimentales, sino mentes independientes que tienen el valor de su época y conocen nuevos dioses" ${ }^{26}[\mathrm{LW}, 96]$. En suma, Goethe es un tirano, anclado en la grandeza fósil de su rostro de piedra, que desea dominar el tiempo. "Sólo es el tiempo", dice para legitimarse esta enemiga íntima, profunda, poderosa de Goethe, que sin embargo siempre oculta su enemistad, aquella que viene inspirada por el más torvo y estrecho nacionalismo. $\mathrm{Y}$ entonces, cuando ha presentado a este personaje con los tintes de lo repulsivo y lo mezquino, en el capítulo quinto, ese excursus cervantino de historias de enamorados, Adela relata el verdadero objetivo de la visita: que Lotte intervenga para detener ese matrimonio imposible entre Otilia y el hijo de Goethe, esa síntesis renovada de la Alemania eterna (pues Otilia siempre se presenta como una nueva Lotte) y el espíritu de Goethe. Por supuesto, Mann presenta el interés de Adela por Otilia de un modo extremo, casi lésbico. "Déjeme hablarle, desahogar mi oprimido corazón e implorarle que favorezca a un ser querido que está en peligro"27. Lo que de

22 LW, 137/CW, 92. El crescendo de la denuncia de Adela, y la complicidad igualmente intensa de Carlota, es magistral. Mann retrata a dos filisteas cuchicheando secretos, logrando inspirar al lector una entrañable simpatía por el desinhibido vitalismo de la Vulpius, a la que imaginamos haciendo plenamente feliz a Goethe.

23 LW, 138/CW, 92. "Sie aber ein Bild des Leben gewesen war".

24 "Du kannts, du kannts mich nicht verlassen!". LW, 138/CW, 92.

$25 \mathrm{LW}, 143 / \mathrm{CW}, 95$. Aquí Adela pretende que la actitud de Goethe hacia las mujeres venga definida por la actitud que ella considera que ha de tener respecto de lo que la propia Adema representa. Ella así se promueve a único tipo de mujer al que Goethe debería ser sensible. Esto le hace denunciar la actitud de "männliches Partisanentum" que presenta "in komischem Lichte" lo que Adela entiende son "unser Zartestes".

26 Cf. LW, 144/CW, 96. "Wir sind Kinder des neuen Lebens [...] ein neues Geschlecht, und sind gar keine sentimentalen Ziegen, sondern selbständige, fortgeschrittene Köpfe mit dem Mute zu ihrer Zeit und Ihrem Geschmack und kennen schon neue Götter".

27 "Lassen Sie mich erzählend mein bedrängtes Herz soulagieren und bei Ihnen bitten für ein liebes, gefährdetes Geschöpf, das mir solcher Fürbitte wegen wohlgar recht böse wäre, obgleich es sie so sehr benötigt als ver- 
esta manera se quiere obstaculizar es que la herencia de Goethe se perpetúe en una Alemania que sólo tendrá entonces una opción, amarse a sí misma en una ideología plenamente nacionalista.

Y la historia cervantina que cuenta Adela trata del desencuentro del prusianismo de Otilia con el espíritu cosmopolita y profrancés de los Goethe, la historia del supremacismo racial prusiano, la emergencia del nacionalismo extremo y todos sus pretendidos valores antidionisíacos, antipopulares: "la castidad, la obediencia, la renuncia, el espíritu del sacrificio, la disciplina colectiva, la inmolación a la patria"28. Este era el sentir de Otilia, aunque se dejaba llevar por la francofilia que imponía las victorias de Napoleón. En suma, mientras en el ámbito público se profesaba el culto a Francia, en el ámbito íntimo, secreto, casi de conspiración, dice Mann [103] se impulsaba una doble vida entregada al nacionalismo. Eso es lo que simbolizaba su compromiso público con Augusto y su amor secreto al oficial prusiano al que Adela inspiraba. Esta vida pública hizo que Goethe se interesara por ella y la preparara para su hijo. Este, mientras tanto, era víctima de un complejo de inferioridad y de una inseguridad edípica completa, dada su dudosa legitimidad. Así que Otilia aceptaba la relación dejándose llevar por su sentido trágico del deber, no por su inclinación amorosa. Lo que se juega en este relato, por tanto, es la erosión del espíritu europeo de Goethe, su oposición al Sonderweg alemán, al aislamiento hostil de los pueblos de Europa, a la sublimación de la cultura como forma de entender la superioridad alemana. En suma, de nuevo la genealogía del nazismo, que en ningún otro sitio que en la silueta mezquina de Adela encuentra su cuna. Sobre este germen, Goethe dice: "Sus intenciones son buenas, lo sé. Pero no son suficientes las buenas y puras intenciones. Hace falta considerar las consecuencias de nuestra actitud. La suya me asusta, porque bajo una forma noble, aunque inofensiva, habita algo espantoso, que se manifestará algún día en los alemanes, acompañado de las más groseras locuras" 29 .

Lo que se denunciaba de este nacionalismo era la pretendida síntesis del ideal griego de cultura con el heroísmo prusiano ${ }^{30}$. Napoleón, frente a la supremacía prusiana, preparaba una confederación renana con las tierras del sur y así abrir camino a una Europa unida. Goethe, que había animado estos ideales, tras la derrota de Napoleón, estaba solo y se sentía incapaz de contener el nacionalismo. Por fin, como dice Adela, Napoleón reveló y rebeló a los alemanes ${ }^{31}$. Prendido el nacionalismo de la inteligencia demoníaca de Adela Schopenhauer en el pecho sentimental de Otilia, las relaciones con Augusto se estancaron. Fue el acontecimiento de 1813, la derrota de Napoleón, "el maravilloso impulso de Prusia”, el "levantamiento de los

dient". LW, 149/CW, 99.

28 LW, 154/CW, 102. "Der Armut und [...] den beiden anderen mönschichen Tugenden und Forderungen; der Keuschheit und dem Gehorsam; es galt der Entsagung, der Bereitschaft zum Opfer, der zuchtvollen Gemeinchaft, dem Leben fürs Vaterland".

29 Cf. LW, 166-167/CW109. Esta alabanza de la ética de la responsabilidad, frente a la ética de la intención, implica una prospectiva, una capacidad de pronóstico, que aquí tiene una dimensión legitimadora de la posición de Mann, que se autorrepresenta como el momento en el que Goethe regresa de su tumba. Si al Goethe le llegara el más pequeño eco de esas locuras, "in Ihrem Grabe umkehren würden”. Eso es exactamente lo que decide a Mann a resucitarlo en este libro.

30 "Die Verkörperung hellenischer Schönheit im Verein mit väterländischem Freiheitsheroismus in ihm erblickte“ LW, 183/CW, 119.

31 Por supuesto, el juego de palabras no es aquí de Mann El texto dice lo siguiente: "Soll man's dem Cesar als Schuld anrechnen oder Verdienst, wie er uns den Sinn gewendet und uns zi uns selbst geführt?” Cf. LW, 190/ CW, 123. 
patriotas", la "conspiración patriótica", todo ello transformaron la mente de Otilia, que impulsó "secretos contactos" que pusieron en peligro su vida. Al final, el grupo de muchachas se enamora de un soldado prusiano herido al que esconden en lo más hondo del corazón, "nuestro ídolo, el guerrero ideal", "un verdadero hombre" 32 la materialización de la poesía. Los ánimos se exaltaron y electrizaron y el objetivo del grupo de muchachas fue "reducir París a cenizas"33. Adela también se sintió entonces reconocida por el soldado herido. "También a mí, joven desprovista de belleza", susurra a Lotte ${ }^{34}$.

Frente al espíritu fatídico de aceptación de la tragedia de Otilia, esa inclinación hacia "las tinieblas y el sufrimiento", Adela es la fría inteligencia puesta al servicio de la exaltación nacional que ella no siente, pero que admira en Otilia, dispuesta a enrolarse en el cuerpo de amazonas que arman en Berlín gentes como Fichte y Schleiermacher. Por supuesto, Adela es demasiado consciente de pertenecer a una aristocracia del espíritu como para bendecir ese entusiasmo nacionalista ya degradado que llegaba hasta el corazón de los despreciables tenderos. "Todo el pueblo quería ser poeta, y nadaba en apocalipsis, visiones proféticas, sueños de sangre, de odio y de venganza" 35 . Ese frío nacionalismo que desprecia al pueblo cuando participa de esa emoción, esa arrogancia intelectualizada, caracteriza el ambiente en el que Goethe y su herencia no pueden vivir. Sin atmósfera adecuada, el hijo de Goethe perdió el rumbo, mientras que Otilia lo interpretó como una "tristeza romántica y satánica" atractiva, a la que se aficionó. Así que todo quedó bloqueado. Adela, sin embargo, no cesaba en su ambición de separar a Otilia respecto de Augusto, y veía a su amiga como el pajarillo que está fascinado por la serpiente antes de ser engullido por ella. Esta afección era insoportable para Adela ${ }^{36}$. Ahora deseaba implicar a Lotte en esta operación de separación, de romper aquello que no estaba basado sobre afinidades electivas, y ese era el motivo de su visita a la antigua amante de Goethe. Ahora se trataba de inclinar a la mujer que simbolizaba Alemania entera al ideal prusiano de militarismo y lograr que el propio Goethe rompiera el lazo de Augusto con Otilia. Y fue entonces cuando Adela deja caer el motivo más íntimo de esta aspiración: "Pues para una fea es más fácil rendir conjuntamente con una hermosa un culto al recuerdo del desaparecido héroe de sus sueños, como hicimos nosotras, que gustar con ella la dicha del desigual reparto de su presencia física" ${ }^{37}$. En esta refinada confesión de amor, que goza de compartir con Otilia el amor al fantasma de un tercero, el soldado prusiano, porque no puede aspirar a gozar del amor directo de ella, ni tolera ver que entre ellas se levanta el obstáculo de otro cuerpo que haga feliz a Otilia, aprecia-

32 "Unser Idol, den preussischen Helden [...] einen wirklichen Jüngling”. LW, 177/CW, 115.

33 "Das Vaterland zu befreien und Paris in Asche zu legen”. Cf. LW, 177/CW, 116.

34 La literalidad del discurso de Adela es mucho más refinada y retorcida: "Ein gemessener Teil von Ferdinands Dankbarkeit mochte auf mich unschönes Ding entfallen”. Cf. LW, 180-181/CW, 118.

35 "Das ganze Volk dichtete, es schwelgte und schwamm in Apokalypsen, Prophettengesichten, in blutigen Schwärmereien des Hasses und der Rache". LW, 193/CW, 125.

36 "Sah ich doch, dass sie gebannt war von ihn und von dem Gedanken, die Seine zu werden, wie das Vögelschen von der Schlange". LW, 216/ CW, 139.

37 "Denn immerhin ist es für eine Hässliche leichter, zusammen mit einer Schönen den Kult der Erinnerung an den entschwundenen Helden ihrer Träume zu betreiben, wie wir es nun wieder taten, als sich mit ihr in das ungleiche Glück seiner körperlichen Gegenwartzu teilen”. LW, 210/ CW, 135. La traducción altera un poco la segunda parte de la frase. Debería decir "que compartir con ella la dicha desigual de su presencia física". Sólo en esta traducción más literal se descubre lo que deseaba Adela, a saber, estar unida con toda su alma a Otilia, sin ningún cuerpo físico que significa un estorbo y un muro entre las dos amigas. 
mos entonces la extraordinaria crueldad de Thomas Mann, tanto como su complejo sentido de la sugerencia. Lo que esta mínima historia lésbica tenga que ver con esta genealogía de la desgracia alemana es, sin embargo, un poco confuso. Quizá no organizaba sino un juego de reflejos narcisistas y quizás, al destacar esta sobrevenida soledad, Mann despreciaba la repulsiva inteligencia que separó a Alemania de la amistad de los pueblos civilizados europeos. Quizá la clave está en el control del alma de la ingenua Otilia en el que Adela concentra su endiablada y sutil voluntad de poder. Esa inteligencia demoníaca representada por la repulsiva señorita Schopenhauer, el retrato equivalente en mujer al repulsivo y feo Nafta, no amaba a Prusia, ni al héroe prusiano herido. Amaba y aspiraba a poseer a Otilia, la belleza tímida y burguesa que representaba a la eterna Alemania, una tentación que Goethe jamás conoció al dejar en libertad a Lotte. Y a su manera, Adela poseía a Otilia con un poder frío y altanero. Pero también esta historia puede significar otra cosa. Quizá esta novela muestra que, por un instante, Mann abandonó la potencia mítica del relato, para ceder a una misoginia existencial que tenía que ver con la propia mitificación de su compleja sexualidad de artista, que en el fondo gustaba de los fanciulli, pero no del trato con las mujeres dotadas de una rebuscada agudeza mental. 